\title{
Role of micronized progesterone in prevention of preterm labour in women with previous history of one or more preterm births: a research study at a tertiary care hospital
}

\author{
Rashmi Ahuja, Anupa Sood, Anita Pal, Rita Mittal*
}

KNSHMC, IGMC, Shimla, HP, India

Received: 20 June 2015

Revised: 23 June 2015

Accepted: 13 July 2015

\section{*Correspondence:}

Dr. Rita Mittal,

E-mail: mittaldrrita@gmail.com

Copyright: $\odot$ the author(s), publisher and licensee Medip Academy. This is an open-access article distributed under the terms of the Creative Commons Attribution Non-Commercial License, which permits unrestricted non-commercial use, distribution, and reproduction in any medium, provided the original work is properly cited.

\begin{abstract}
Background: According to the WHO, 3 million newborns die each year due to complications related to pregnancy and childbirth and $99 \%$ of these deaths occur in the developing countries. Preterm birth is a leading cause of neonatal and infant mortality as well as short and long term disability. The mechanism responsible for preterm labour are not exactly known, may be multifactorial and preventable with timely and appropriate treatment.

Methods: This was a prospective double blinded randomized placebo controlled study conducted in the department of Obstetrics and Gynaecology, Kamla Nehru State hospital for mother and child, Shimla. Total 80 patients with asymptomatic high risk singleton pregnancy between 24-28 weeks were included in the study. They were randomly allotted to receive either the progesterone tablet $100 \mathrm{mg}$ intravaginally (Study group) or an identical looking placebo (Control group).Thus both the groups included 40 subjects each. The treatment was continued till 34 weeks of gestation or till PROM/ delivery, whichever was earlier. Method of termination, gestational age at time of delivery, mode and type of delivery, birth weight, apgar score, maternal and perinatal outcome were noted and compared in both groups. All the parameters were statistically analysed by mean \pm S.D, proportion, frequency, chi-square test. Percentage reduction in the quantitative variables was calculated using the formula of $(\mathrm{n}-\mathrm{t}) / \mathrm{n} \times 100$.

Results: The incidence of preterm deliveries in the present study was found to be $9.88 \%$. Both the groups were comparable in respect of age, parity, BMI, socioeconomic status, occupation and gestational age at first antenatal visit. There was similarity in both groups in respect to number of previous preterm deliveries and cervical length. The incidence of preterm delivery in the study group was $12.5 \%$ and in the control group was $35 \%$.

Conclusions: The study concluded that progesterone use was associated with $64.2 \%$ reduction in the incidence of preterm delivery $(\mathrm{p}=0.029)$. Antenatal administration of progesterone reduces the risk of preterm birth before 37 weeks and 34 weeks as well as the risk of a newborn being born with a birth weight of less than 2500 gms.
\end{abstract}

Keywords: High risk pregnancy, Progesterone, Preterm birth, Perinatal outcome

\section{INTRODUCTION}

Preterm birth, according to WHO, is defined as birth before 37 completed weeks of gestation. Preterm delivery is the single most important obstetrical complication associated with perinatal morbidity and mortality. It is directly responsible for $75-95 \%$ of all neonatal deaths not resulting from lethal congenital malformation and of those who survive, $10-15 \%$ have significant handicaps. In developed countries, the incidence of preterm birth is about $7-12 \%$ of all deliveries and among these $1 / 3^{\text {rd }}$ occur before 34 completed weeks. The prevalence in developing countries is even higher. In India, the incidence of preterm 
delivery is $10 \%-69 \% .^{2}$ The incidence of preterm in $\mathrm{KNH}$, Shimla is $10-20 \%$.

The mechanism responsible for preterm labour is not known. Concurrent obstetrical abnormalities like abruptio placenta, placenta praevia, multiple gestation, hypertensive disorders, IUGR etc. are identifiable only in $40 \%$ of cases, but the remainder occur unexpectedly and without any cause. ${ }^{3}$ Progesterone treatment for preventing preterm birth has been the subject of several relatively small trials beginning in 1960s.

Keeping this in view, we conducted a study on women at high risk for preterm delivery i.e. with documented history of preterm birth at $<37$ weeks of gestation and to evaluate whether prophylactic administration of progesterones can reduce the incidence of preterm birth in such high risk population.

\section{METHODS}

This prospective double blinded randomized placebo controlled study was conducted in the department of Obstetrics and Gynaecology, Kamla Nehru State hospital for mother and child, Shimla. Total 80 patients with asymptomatic high risk singleton pregnancy between 24 28 weeks were included in the study. They were randomly allotted to receive either the progesterone tablet $100 \mathrm{mg}$ intravaginally (Study group) or an identical looking placebo (Control group). Thus both the groups included 40 subjects each. The treatment was continued till 34 weeks of gestation or till PROM/ delivery, whichever was earlier. Gestational age was calculated from the first day of her LMP and/or by means of bimanual examination and/or by ultrasound measurements before 20 weeks.

\section{Exclusion criteria}

1. Documented evidence of uterine malformation

2. Documented evidence of short cervical length $<15 \mathrm{~mm}$ detected on TVS at 22-26 weeks.

3. Prophylactic cerclage operation

4. Multiple gestation

5. Foetal malformation

6. Patients with PROM

7. Patients delivering within 2 weeks of initiating progesterone therapy

8. Patients with therapeutic preterm delivery

9. Other medical disorders.

After detailed history, GPE and Systemic examination, detailed obstetrical examination was done. P/S examination was done at the time of recruitment to note presence of any discharge and to check $\mathrm{pH}$ of vagina. Whiff test was done and endocervical swabs taken for culture and sensitivity. Routine investigations were done for all the patients followed by ultrasonography. TAS was done to look for gestational age, placental localization, amniotic fluid and congenital anomalies. TVS was done during second and early third trimester to look for cervical length and internal os diameter. After taking informed consent, patients were allocated randomly into two groups and patients were followed up, two weekly till $30^{\text {th }}$ week of pregnancy and thereafter, weekly till delivery. Method of termination, gestational age at time of delivery, mode and type of delivery, birth weight, apgar score, maternal and perinatal outcome were noted and compared in both groups. Patient treatment was unblinded after the delivery of last pregnant woman. All the parameters were statistically analysed by mean \pm S.D, proportion, frequency, chi-square test. Percentage reduction in the quantitative variables was calculated using the formula of $(n-t) / n \times 100$

\section{RESULTS}

The incidence of preterm deliveries in the present study was found to be $9.88 \%$. Both the groups were comparable in respect of age, parity, BMI, socioeconomic status, occupation and gestational age at first antenatal visit. There was similarity in both groups in respect to number of previous preterm deliveries and cervical length as shown in Table 1.

Table 1: Shows no. of previous preterm deliveries and cervical length in both groups.

\begin{tabular}{|c|c|c|c|c|c|}
\hline \multirow{2}{*}{ Variable } & \multicolumn{2}{|l|}{ Cases } & \multicolumn{2}{|l|}{ Control } & \multirow{2}{*}{$\begin{array}{l}P \\
\text { value }\end{array}$} \\
\hline & Number & $\%$ age & Number & $\%$ age & \\
\hline \multicolumn{6}{|c|}{ No of Previous Preterm } \\
\hline 1 & 9 & 2.5 & 0 & 5 & \multirow{2}{*}{0.499} \\
\hline$>1$ & 1 & 7.5 & 0 & 5 & \\
\hline \multicolumn{6}{|c|}{ Cervical Length } \\
\hline$<2.8 \mathrm{~cm}$ & 5 & 7.5 & 8 & 5 & \multirow{2}{*}{0.407} \\
\hline$\geq 2.8 \mathrm{~cm}$ & 5 & 2.5 & 2 & 5 & \\
\hline
\end{tabular}

Both the groups were comparable in respect to beginning of treatment i.e. $67.5 \%$ in study group and $65 \%$ in control group started their treatment between 24-26 weeks of gestation. Similarly $32.5 \%$ of subjects in the study group and $34.5 \%$ in the control group initiated treatment at 2628 weeks.

Out of 40 study subjects, $1(2.5 \%)$ was admitted for threatened preterm, given tocolysis but delivered prematurely, whereas, $3(7.5 \%)$ subjects in the control group were admitted for threatened preterm, given similar treatment, but $2(5 \%)$ delivered prematurely, with a $\mathrm{p}$ value of 0.307 , which was not statistically significant.

All the subjects were followed up till delivery and the period of gestation at the time of delivery was calculated. It was observed in the present study that there was 
significant improvement in the period of gestation at the time of delivery in study group, as shown in

The incidence of preterm delivery in the study group was $12.5 \%$ and in the control group was $35 \%$. Thus progesterone was associated with $64.2 \%$ reduction in the incidence of preterm delivery $(\mathrm{p}=0.029)$. When we tried to correlate the outcome in present pregnancy with number of previous preterm deliveries, it was observed that with history of previous one preterm delivery, there was $29(72.5 \%)$ subjects in study group ,out of which $28(96.5 \%)$ had term delivery and only $1(3.5 \%)$ delivered preterm. Among 30 controls, 10 (33.3\% had preterm delivery and $20(66.6 \%)$ delivered at term. These parameters were statistically significant with $\mathrm{p}$ value of 0.003 .

Table 2: Depicting the POG at the time of delivery in both groups.

\begin{tabular}{|llllll|}
\hline Sr. & Pog & Cases & \multicolumn{3}{c|}{ Controls } \\
No. & N=40 & \%Age & $\mathrm{N}=40$ & $\%$ Age \\
\hline 1. & $\begin{array}{l}<37 \\
\text { Weeks }\end{array}$ & 5 & 12.5 & 14 & 35 \\
\hline 2. & $\begin{array}{l}>37 \\
\text { Weeks }\end{array}$ & 35 & 87.5 & 26 & 65 \\
\hline
\end{tabular}

With previous history of $>1$ preterm delivery, there were 11 subjects in the study group, out of which $7(63.7 \%)$ delivered at term and $4(36.3 \%)$ delivered prematurely. In the control group, there were total of 10 subjects, out of which $6(60 \%)$ delivered at term while remaining delivered prematurely. These figures were comparable to each other and not statistically significant ( $\mathrm{p}$ value $=0.609$ ). Thus it was found that progesterone use significantly prolonged the period of gestation in women with previous history of one preterm delivery as compared to women with history of more than one preterm birth.

Mode of delivery and Apgar score were similar in both the groups in our study. Mean birth weight in the study group was more i.e. $2580+-507$ gms as compared to that of control group i.e. $2360+-512$ gms, though the difference was not statistically significant $(\mathrm{p}=0.06)$.

\section{Perinatal outcome}

All the neonates were born alive. Out of 40 neonates in the study group, only $7(17.5 \%)$ were admitted to NBN, out of which 3 were term and 4 were preterm. In the control group, $17(42.5 \%)$ neonates were admitted to NBN, out of which 4 were term and 13 were preterm showing that neonates admitted to NBN decreased significantly in the progesterone group (17.5\% Vs $42.5 \%)$.

It was observed that most common neonatal complication was respiratory problem seen in 6 out of 7 babies in the study group and in 14 out of 17 babies in the control group. Incidence of neonatal jaundice and neonatal death were similar in both the groups i.e. $2.5 \%$ vs $2.5 \%$.
Table 3: Depicts the comparison of stay of newborn babies in the NBN.

\begin{tabular}{|lllllll|}
\hline Sr. & Stay In & \multicolumn{2}{c}{$\begin{array}{l}\text { Study } \\
\text { Group }\end{array}$} & \multicolumn{2}{l|}{$\begin{array}{l}\text { Control } \\
\text { Group }\end{array}$} & \\
\cline { 3 - 6 } & NBN & No & $\%$ & No. & $\%$ & \\
\hline 1. & $<24$ Hrs. & 2 & 5 & 4 & 10 & 0.073 \\
\hline 2. & $\begin{array}{l}\text { 24hrs.--- } \\
\text { 1wk. }\end{array}$ & 4 & 10 & 11 & 27.5 & 0.049 \\
\hline 3. & $>1$ wk. & 1 & 2.5 & 2 & 5 & 0.499 \\
\hline
\end{tabular}

\section{DISCUSSION}

The timely onset of labor and birth is a critical determinant of perinatal outcome. Preterm birth represents a syndrome rather than a diagnosis because the etiologies are varied. Approximately $20 \%$ of preterm deliveries are iatrogenic and are performed for maternal or fetal indications, including, among others, severe preeclampsia, placenta previa, monochorionicmonoamniotic twins, cholestasis, intrauterine growth restriction, and nonreassuring fetal testing. Of the remaining cases, approximately $20 \%$ to $30 \%$ occur in the setting of preterm premature rupture of the membranes (PPROM), $20 \%$ to $25 \%$ result from intra-amniotic infection and/or inflammation, and the remaining $25 \%$ to $30 \%$ are due to spontaneous (unexplained) preterm labor. ${ }^{4,5}$ Many investigators have attempted to develop effective preventive strategies and treatment. Of all these, the early detection of pregnant women at high risk for preterm delivery could be the best way to prevent preterm birth. Thereby bed rest, cervical cerclage, treatment of bacterial vaginosis and prophylactic use of progestogens could be one of the management in the high risk population. Estimates suggest the rate of recurrent preterm birth in this group of women is $22.5 \%,{ }^{6}$ which is 2.5 times increased relative risk when compared with women with no previous spontaneous preterm birth. ${ }^{7}$ For women with a history of a single preterm birth, the recurrence risk in a subsequent pregnancy is approximately $15 \%$, increasing to $32 \%$ where there have been two previous preterm births. ${ }^{8}$

Natural micronized progesterone was chosen as it is safe, readily available and undergoes strict quality control. The vaginal route was chosen due to its better patient compliance and improved efficacy through enhanced drug delivery to target tissues. The rationale behind use of progesterone is

1. It blocks the oxytocin effect of PGF2 $\alpha$ and $\alpha$ adrenergic stimulation ,thus suppressing the calciumcalmodulin myosin light chain kinase system ${ }^{1}$

2. It also suppresses genes necessary for uterine contractility, upregulating systems like NO and suppressing the release of cytokines and prostaglandins, thus maintaining the uterine quiescence ${ }^{9}$ 
3. It also prevents the rejection of the fetus by the mother by suppressing the cellular component of the immune system $^{9}$

Previously synthetic progesterones were being used but recent trials ${ }^{1,10}$ have reported success of natural progesterone in preventing recurrent preterm delivery in women at high risk. The administration of natural progesterone has fewer metabolic effects or haemodynamic effects and is considered to be non teratogenic, decreases number of episodes of uterine contractions as well as the incidence of preterm birth in women at high risk. Above fact has rekindled interest in developing strategy for preventing preterm delivery.

Risk Factor Scoring. A number of risk factors for preterm birth have been identified. Several scoring systems have been developed based on these historic/epidemiologic risk factors and daily habits in an attempt to predict women at risk for preterm birth. Unfortunately, reliance on risk factor-based screening protocols alone will fail to identify over $50 \%$ of pregnancies that deliver preterm (low sensitivity) and the majority of women who screen positive will ultimately deliver at term (low positive predictive value). ${ }^{11,12}$ The single greatest risk factor for preterm birth is a history of a prior unexplained spontaneous preterm delivery.

Table 4: Showing various risk factors responsible for preterm birth.

\begin{tabular}{|ll|}
\hline $\begin{array}{l}\text { Nonmodifiable } \\
\text { Risk Factors }\end{array}$ & $\begin{array}{l}\text { Potentially } \\
\text { Potentially Modifiable } \\
\text { Risk Factors }\end{array}$ \\
\hline $\begin{array}{l}\text { Prior preterm birth } \\
\text { African-American } \\
\text { race }\end{array}$ & \\
Age $<18$ years or $>$ & \\
40 years & Cigarette smoking \\
Poor nutrition & Illicit drug use \\
Low prepregnancy & Anemia \\
weight & Bacteriuria/urinary tract \\
Low socioeconomic & infection \\
status & Gingival disease \\
Absent prenatal care & Lower genital tract \\
Cervical injury or & infections (including \\
anomaly & bacterial vaginosis, Neisseria \\
Uterine anomaly & gonorrhoea, Chlamydia \\
Excessive uterine & trachomatis, Group B \\
activity & Streptococcus, Ureaplasma \\
Premature cervical & urealyticum, and \\
dilatation (> 2 cm) & Trichomonas vaginalis) \\
or effacement & High personal stress \\
(> 80\%) & Strenuous work/work \\
Overdistended & environment \\
uterus (twins, & \\
polyhydramnios) & \\
Vaginal bleeding & \\
& \\
\hline
\end{tabular}

Sonographic cervical length measurement: A strong inverse correlation exists between residual cervical length as measured by transvaginal ultrasound and preterm birth. ${ }^{13,14}$ If the cervical length is < 10th percentile for gestational age in the mid second trimester, the pregnancy is at a sixfold increased risk of delivery prior to 35 weeks. ${ }^{13}$ A cervical length of $<15 \mathrm{~mm}$ at 22 to 24 weeks occurs in < $2 \%$ of low-risk women, but is predictive of delivery prior to 28 weeks and 32 weeks in $90 \%$ and $60 \%$ of cases, respectively. ${ }^{14}$

Biochemical Tests: A number of biochemical and endocrine markers (including estriol, corticotrophinreleasing hormone, and activin A) are under investigation to determine whether they can be used to identify women at risk for preterm birth. The only test that is currently FDA approved and recommended by The American College of Obstetricians and Gynecologists (ACOG) for this indication is the measurement of fetal fibronectin (fFN) in cervico-vaginal secretions. ${ }^{15,16}$ Elevated levels of cervico-vaginal $\mathrm{fFN}$ (defined as $>50 \mathrm{ng} / \mathrm{mL}$ ) at 22-0/7 through 34-6/7 weeks of gestation are associated with an increased risk of preterm birth. ${ }^{15}$ However, in a low-risk population, the positive predictive value of a positive fFN test at 22 to 24 weeks of gestation for spontaneous preterm delivery prior to 28 weeks and 37 weeks of gestation is only $13 \%$ and $36 \%$, respectively. ${ }^{16}$ The primary value of this test lies in its negative predictive value $(99 \%$ of patients with a negative fFN test will not deliver within 7 days ${ }^{17}$ ), which may prevent unnecessary hospitalization and medical intervention.

\section{CONCLUSION}

It was concluded from the present study that the use of progesterone supplementation may be appropriate in women considered to be high risk for preterm births with a history of prior preterm birth due to unknown factors. Progesterone also reduces neonatal morbidity and improves the birth weight.

Funding: No funding sources Conflict of interest: None declared

Ethical approval: The study was approved by the Institutional Ethics Committee

\section{REFERENCES}

1. Da Fonseca EB, Bittar RE, Carvalho MH, Zugaib M. Prophylactic administration of progesterone by vaginal suppository to reduce the incidence of spontaneous preterm birth in women at increased risk. Am J Obstet Gynecol 2003;188:419-24.

2. Singh U, Singh N, Seth S.A prospective analysis of etiology and outcome of preterm labor. J obstet gynecol India 2007;57(1):48-52.

3. Johnson JW, Austin KL, Jones GS, Davis GH, King TM. Efficacy of 17 alpha-hydroxyprogesterone caproate in prevention of premature labor. $\mathrm{N}$ Engl $\mathrm{J}$ Md. 1975;293:675-80. 
4. Lockwood CJ, Kuczynski E. Risk stratification and pathological mechanisms in preterm delivery. Paediatr Perinat Epidemiol. 2001;15(suppl S2):7889.

5. Ananth CV, Vintzileos AM. Epidemiology of preterm birth and its clinical subtypes. J Matern Fetal Neonatal Med. 2006;19:773-82.

6. Petrini J, Callaghan W, Klebanoff M, Green N, Lackritz E, Howse J, et al. Estimated effect of 17 alpha hydroxyprogesterone caproate on preterm birth in the United States. Obstet Gynecol. 2005;105:267272.

7. Mercer BM, Goldenberg RL, Moawad AH, Meis PJ, Iams JD, Das AF, et al. The preterm prediction study: effect of gestational age and cause of preterm birth on subsequent obstetric outcomes. Am J Obstet Gynecol. 1999;181(5 part 1):1216-21.

8. Carr-Hill RA, Hall MH. The repitition of spontaneous preterm labour. BJOG. 1985;92:921-8.

9. Meis PJ, Connors N. Progesterone treatment to prevent preterm birth. Clinic Obstet and gynaecol 2004;47(4):784-95.

10. Creasy RK, Gummer BA, Liggins GC. System for predicting spontaneous preterm birth. Obstet Gynecol.1980;55:692-695.

11. Mercer BM, Goldenberg RL, Das A, et al. The preterm prediction study: a clinical risk assessment system.Am J Obstet Gynecol. 1996;174:1885-1893.

12. Iams JD, Goldenberg RL, Meis PJ, et al. The length of the cervix and the risk of spontaneous premature delivery. National Institute of Child Health and Human Development Maternal Fetal Medicine Unit Network. N Engl J Med. 1996;334:567-72.

13. Heath VC, Southall TR, Souka AP, et al. Cervical length at 23 weeks of gestation: prediction of spontaneous preterm delivery. Ultrasound Obstet Gynecol. 1998;12:312-317.

14. Lockwood CJ, Senyei AE, Dische MR, et al. Fetal fibronectin in cervical and vaginal secretions as a predictor of preterm delivery. $\mathrm{N}$ Engl $\mathrm{J}$ Med. 1991;325:669-74.

15. Goldenberg RL, Mercer BM, Meis PJ, et al. The preterm prediction study: fetal fibronectin testing and spontaneous preterm birth. NICHD Maternal Fetal Medicine Units Network. Obstet Gynecol. 1996;87:643-8.

16. Iams JD, Casal D, McGregor JA, et al. Fetal fibronectin improves the accuracy of diagnosis of preterm labor. Am J Obstet Gynecol. 1995;173:1415 .

Cite this article as: Ahuja R, Sood A, Pal A, Mittal $\mathrm{R}$. Role of micronized progesterone in prevention of preterm labour in women with previous history of one or more preterm births: a research study at a tertiary care hospital. Int J Reprod Contracept Obstet Gynecol 2015;4:1176-80. 